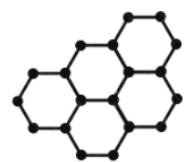

ICONSMAT

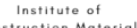

Content list available at ICONSMAT

Journal of Construction Materials

Journal homepage: www.iconsmat.com.au/publication
Article history:

Received 12 June 2021

Received in revised form

10 July 2021

Accepted 24 July 2021

Available online 24 July 2021

\title{
Challenges and Opportunities of E-Procurement in the Construction Industry
}

\author{
Mansur Hamma-adama ${ }^{1 *}$, Abdul-Basit Sa'eed Ahmad ${ }^{1}$ \\ ${ }^{1}$ Lecturer with the Department of Civil Engineering, Kaduna Polytechnic, PMB 2021 Kaduna, Nigeria \\ *Correpsonding author: Phone: +234(0)8037667944; E: m.hammaadama@rgu.ac.uk
}

\begin{abstract}
Construction Industry is evolving amid the fourth industrial revolution. Transportation, commerce, manufacturing and many other industries ripened the current technological advancement and are striving to utilise every development in the IT sector. The procurement of construction works is known to be very conventional and backward in the adoption of digitalisation. The construction industry's procurement and supply chain are blamed for the most inflated cost of construction projects, mainly attributed to a lack of transparency and trust between the industry stakeholders. This research explores the challenges of E-procurement adoption in the industry and identifies the potential opportunities for its usage. This investigation's data are acquired through interviews, and the data are analysed using qualitative content analysis. This study reveals compounding challenges (i.e., corruption and lack of commitment) that lead to the failure of such efforts in Nigeria and the potential prospects (i.e., transparency and efficiency). This study is essential in developing a more effective and transparent process of procurement so that the Nigerian construction industry is not be left behind in the fastdigitalising markets.
\end{abstract}

DOI: 10.36756/JCM.v2.4.7 (C2021 Institute of Construction Materials

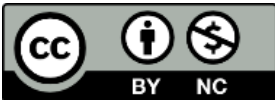

\section{Keywords}

Challenges, construction industry, corruption, E-procurement, Nigeria, opportunities. 


\section{Introduction}

The built environment, and the deficiency in the needed infrastructural development is a significant factor defining most developing economies. The evolutions required to place such countries in the league of world-class nations with the state-of-the-art infrastructures are governed by prudent management of their procurement process, ensuring fiscal responsibility and strengthening their known conventional procurement process marred by sharp practices backwardness. The adoption of digitalised procurement (i.e., E-procurement) would enhance the business of requisitioning and ordering purchases within and outside the construction market. It also ensures streamlining of exact contract terms and identifying approved suppliers to perfect delivery. This way, fraudulent practice in the supply chain of materials and labour can be checked and curbed to the minimum. However, the lack of awareness from the industry players as well as governments on the benefits of deploying Eprocurement in ensuring fiscal responsibility poses a challenge. The inadequate or deficient ICT infrastructure hampers its deployment. Still, such can be tackled through prudent investment. Provision of needed Technical Know-how serves as an opportunity to expand and deepen E-governance relative to the construction industry and the built environment. This paper is an extended conference paper presented at the 2020 International engineering conference and exhibition (Riyadh, Saudi Arabia). The conference paper [1] was based on secondary data (literature-based); on the other hand, this paper presents the challenges and opportunities from industry players (based on primary) on the adoption of E-procurement as a way of enhancing the construction industry of developing economies.

\section{Literature review \\ Blockchain Technology}

Blockchain technology (BCT) was created in 2009 as a result of Satoshi Nakamoto's invention of Bitcoin; $\mathrm{BT}$ is the platform and framework that underpins Bitcoin. BCT is one of the most celebrated inventions in recent years, but it is still one of the most misunderstood [2], [3]. Via business studies and academic and non-academic journals, a significant attempt has been made to introduce a non-technical audience to BT's clear understanding. Despite a high level of consciousness (knowing that it exists), BCT is still poorly understood. BCT, or "blockchain," is a completely distributed mechanism for cryptographically capturing and storing a consistent, immutable, linear event log of transactions between interacted actors.

According to [2], a blockchain consists of five components, including cryptography, peer-to-peer (P2P) network, consensus system, database, and validity rules. The combination of these elements gives blockchain its distinct characteristics. For example, in the event of a challenger [4], cryptographic methods are used to maintain data confidentiality and credibility (i.e., symmetric key or public-key cryptography, cryptographic one-way hash functions etc.). The P2P network is a peer-to-peer network that allows for peer discovery and data sharing. The consensus process is a structure that governs the ordering of transactions in the event that not all parties are truthful (adversarial environment). A ledger is a set of transactions organised into 'blocks' that are cryptographically connected. The validity rules are a series of rules that the network uses to determine whether or not a transaction is legitimate.

Blockchains can minimise the amount of trust required before a transaction, but they do not completely remove the need for trust. In a similar way, validators and/or operators are trusted; in a well-configured environment, participants independently check the status of the system and validate transactions [2].

In the present days, there are several blockchain myths, but the common ones are: 
1. The blockchains are 'trustless.'

2. Blockchains are immutable or 'tamper-proof.'

3. Blockchains are $100 \%$ secure.

4. Blockchains are 'truth machines.'

However, there are corresponding realities to these myths, which are mostly misunderstood by the populace; and these include:

1. Blockchains always require some degree of trust.

2. Network participants can reverse transactions on the blockchain network under specific circumstances.

3. Blockchains are not inherently safer than other schemes.

4. Any blockchain that uses non-native digital assets and/or external data is guilty of 'garbage in, garbage out' $[1,2]$.

Gideon Greenspan, CEO of CoinSciences (Multichain), described blockchain as "a modern kind of database that allows several parties to share a database and easily and securely change it even if they don't trust each other." Furthermore, blockchain is intended to achieve stable and dependable consensus between independent parties over a database of events (for example, "who owns what") amongst self-contained participants with varying motivations and goals.

The open and closed blockchains are the two most common forms. The summary of these types is presented in Table I $[1,2,5]$.

Blockchain is a promising groundbreaking technology that has a wide range of applications. However, [6] argued that scientific data to link old or conventional methods to blockchain approaches are still difficult to come by. Businesses should be aware that the blockchain architecture is still emerging in the same order as its implementation. However, the maturity level of BCT is not yet optimal, so a thorough feasibility analysis is needed for viable implementation. There have been several reported flaws in the use of Bitcoins by many well-known organisations in the United States. Financial companies have expressed concern over using public blockchain (i.e., Bitcoin), operated by anonymous miners and fuelled by an uncontrolled, unpredictable currency [2]. Many organisations remain hesitant to adopt the blockchain because of legal and reputational concerns, despite the fact that auditable transaction documents have been identified as a key innovation in this new system. 
Table 1 - Main types of blockchain segmented by permission model

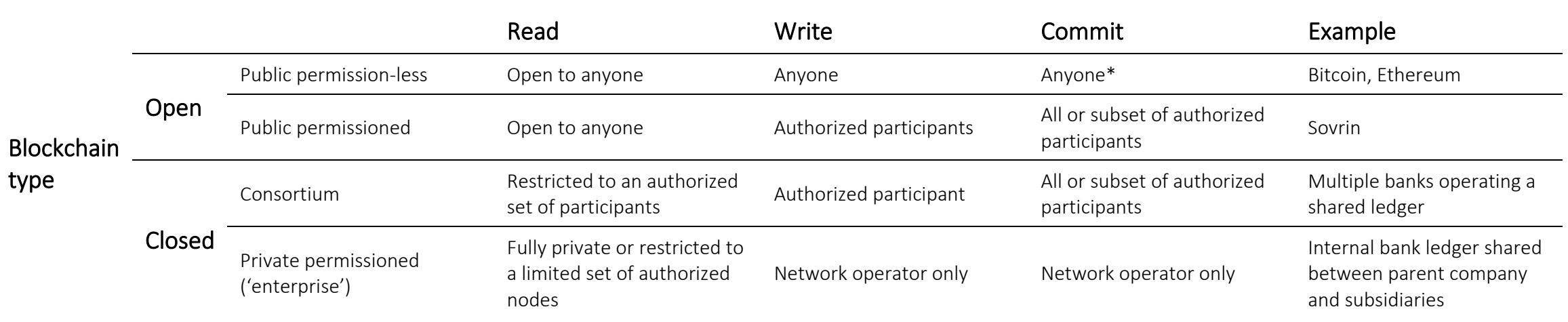

*Requires significant investment either in mining hardware (proof-of-work) or cryptocurrency itself (proof-of-stake model).

Table 2 - Demographic profile of the interviewees

\begin{tabular}{|c|c|c|c|c|}
\hline Interviewees & Organization size & Organization role & Project type involve & Project location \\
\hline Interviewee 1 (CCE) & $>20$ staff (large) & Client development control & Building and Infrastructure & Abuja \\
\hline Interviewee 2 (CEC) & >20 staff (large) & Consultant/Designer & Building and Infrastructure & Kaduna \\
\hline Interviewee 3 (CSE) & 11-20 staff (medium) & Consultant/Designer & Building and Infrastructure & Kaduna and Kano \\
\hline Interviewee 4 (CLA) & >20 staff (large) & Client or Development Control & Building and Infrastructure & Abuja \\
\hline
\end{tabular}




\section{Research method}

This paper aims to present the challenges and opportunities that industry players (designers, constructors, and clients) face in adopting E-procurement to improve the construction industry in emerging economies. Interviews with business experts are used as a primary database, and the transcribed interviews are widely used as a direct source of intelligence [7]. As a result, a holistic approach to content interpretation is thought to be appropriate for this investigation [8]. A nonprobability sample of respondents is used, which is often correlated with exploratory experiments, and such samples are often used to generate theories for further analysis [9, p.8]. According to [10], this approach relied on smaller respondents and was built on a single case qualitative technique.

Face-to-face interviews were conducted, with audio recordings made for transcription purposes. The employed technique encourages interviewees to communicate publicly, share their opinions, and comment on common perspectives in the sensitive environment, allowing the interviewer to collect clear, appropriate, and supplementary data [11].

Samples of four parties who are the key stakeholders are selected in a non-probability method where all the three critical parties (contractors, consultants and client) are represented.

The sample of four parties used is chosen by considering their significance within the industry's choicemaking as well as the need. The interviewees' names are derived using abbreviations as follows: Client Chief Engineer (CCE); Civil Engineer Consultant (CEC); Consultant Site Engineer (CSE); and Client Architect (CLA).

\section{Analysis and results}

The transcribed interviews were further reduced and coded under the two key investigative areas (challenges and opportunities), which are the study's objectives. Adopting the steps in Fig. 1 (as identified by [12]), the analysis of the fetched data was carried out using the interpretation of participants' knowledge, abilities and experiences [13].
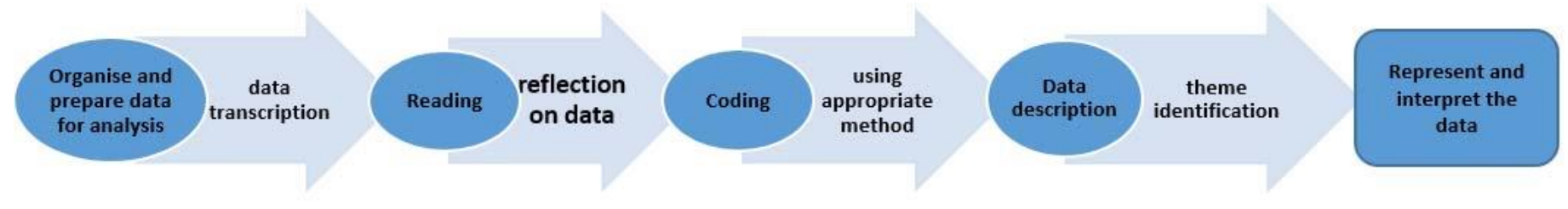

Figure 1 - Data analysis process adopted from [14].

Based on the data analysis, this study is presented in three themes as recognised. The themes include the understanding or knowledge of E-procurement, challenges that hamper the adoption of Eprocurement, and opportunities of adopting E-procurement. In presenting a precise statement of the interviewees, quotations were used to justify the study assertions. 


\section{A. Understanding of E-Procurement in Nigeria}

There is considerable basic knowledge of E-procurement without participation. The awareness level of E-procurement is considerably high with clear understanding compared to previous research undertaken in the E-procurement related fields. For instance, all the study participants revealed that they are aware of E-procurement and demonstrated a clear understanding of this IT-based procurement strategy. The construction practitioners understood E-procurement in the following terms:

"The use of electronic channels to purchase services" CCE;

"The use of an electronic medium in the public procurement to obtain values for goods and services in the construction industry" CEC;

"The use of computer and internet in the process of procuring a construction works" CSE.

Although the practitioners' point of view is that they have never practised or participated in a project where E-procurement is utilised; but, they procured some finished products (i.e. construction materials, equipment and plants) via electronic means.

"...purchase of Laboratory Equipments and construction materials" CCE;

"...purchase of finished goods for the construction industry" CEC

"...purchase of construction materials during construction" CSE

It is then established that there are substantial awareness and knowledge of the E-procurement strategy in the targeted population; however, there is no practical utilisation in the procurement of construction works.

\section{B. E-Procurement Adoption Challenges}

Most of the interviewees never participated in a project where E-procurement was used in procuring construction work. This may be attributed to the current legislative provisions of procuring engineering or construction works in Nigeria. The research participants were asked of any legislative provision on this, and they responded that:

"Not to my knowledge", CCE

Moreover, there is no legislative provision to enforce this type of strategy. The chief client engineer (CCE) confirmed no legislative provision to enforce E-procurement on the construction works. On the other hand, CLA reported that only a few E-procurements were initiated at the Federal Capital Development Authority (FCDA) when Nasir El-Rufa'i was the FCT minister. But the effort subsequently failed, and the E-procurement later became optional.

"...when we launch the E-procurement program, it was essentially the then Minister, Malam Nasiru El-Rufai, he was even ahead of the government. We had our E-procurement program long before the Bureau of Public Procurement (BPP) had an E-procurement program. Till now, I cannot tell you any degree of certainty that the BPP has the available E-procurement program..." CLA 
And, continue further that:

"...when we wanted to launch a pilot for e-procurement, for example, one of the requirements entail having contractors to be registered in our electronic database and that is where we were stocked because most of them were not compliant..." CLA

It was established that there were efforts put into E-governance (including E-procurement strategy) about a decade ago, but the push was not successful because only an individual was championing the movement. That individual left the authority before successful implementation, and no one could succeed him in that direction; hence, all his plans collapsed. Moreover, lack of technical expertise is considered as a prevalent challenge to the adoption of the E-procurement.

"Lack of technical expertise in the procurement arms of institutions is the threat to the prevalent status quo as well as inadequate E-procurement channels" CCE.

CCE also added that inadequate use and poor deployment of E-procurement attributed to the low consideration of this means of procurement. Thus, it suggested encouragement from both government and industry players.

"Inadequate use or deployment of E-procurement in the construction industry, and the way forward is to encourage a paradigm shift that can deepen E-procurement in all business being it government or otherwise" CCE.

In this regard, CEC and CSE suggested prudent competition and transparency encourage the industry players; then, considers proper checks and balances of any platform used.

"There should be prudent competition and transparency. Lack of proper checks and balances of deployed E-procurement channels" CEC

Bribery and kickbacks posed challenges to changing the current mean of procuring construction works; thus, attitudinal change is critical to change the status quo (CEC and CSE).

"Attitudinal changes form the status quo that encourages bribery and kickbacks pose as a great barrier for the deployment of E-procurement in the construction industry" CEC.

On the other hand, CSE added an inefficient delivery process and lack of continuity as additional challenges to this procurement channel's deployment.

"In-efficient delivery process and lack of political stability" CSE

CEC considers the encouragement of E-channels in most government business as a medium to enthrone E-procurement in all public services, which will bring the needed paradigm shift.

\section{E-Procurement Adoption Opportunities}

The e-procurement adoption may be far from realisation based on the previous subsection that presented its adoption challenges. However, the opportunities are very clear to most of the construction professionals who are aware of this innovative route of the procurement process. The CCE sees E-procurement as an improved or more streamlined process of procurement than the conventional process. 
"To streamline procurement processes" CCE.

CEC also supported CCE that E-procurement enhanced the public procurement process and went further with additional opportunities to eliminate corruption and wastages.

"The enhancement of public procurement process that will eliminate underhand practices that encourage corruption and wastages" CEC.

\section{Thematic Finding}

This study sets an enquiry to determine how realistic deploying E-procurement in the procurement of construction works is. The research participants (CCE and CEC) insisted that legislative backing must be enacted to support the deployment of E-procurement to implement this new strategy realistically. Furthermore, it allows enforcement, eliminates selectiveness and abuse of office by the public servants.

"Much realistic backed with legislation and all-inclusive enforcement. This way will eliminate selective application and abuse" CCE

"This way E-governance can be strengthened" CCE.

CEC insisted on the participation of the government in driving the E-procurement and E-governance at large.

"The way forward is the encouragement of e- channels in most government business; this will serve as a medium to enthrone e-procurement in all public services which will bring the needed paradigm shift" CEC.

Ultimately, legislative provision supports the deployment, adoption and enforcement of the Eprocurement at all levels within the construction industry and beyond if such is required. Further on, the future construction industry seems to embrace more environmental and digitalized technologies to tackle the current existing issues [15-26].

\section{Conclusion}

The purpose of this paper was to determine the challenges that hamper the adoption of E-procurement and opportunities in the adoption of E-procurement in the construction industry.

The study reveals the following as significant challenges that hamper the adoption of e-procurement: Lack of technical expertise in this aspect; Corruption or bribery in the system; Lack of commitment by the top management or champion as a driver; Lack of compliance by most engineering firms; and Lack of legislative backing. Also, the study reveals the following as opportunities of e-procurement deployment: Increases transparency; Reduces corruption; Strengthens procurement process (i.e., efficiency), and Opens additional opportunity to explore more innovations (i.e., blockchain). Thus, the innovative way of procurement route can only be realised when there are legislative provision and highlevel commitment by the regulatory bodies. Furthermore, having technical expertise in this area and the stakeholders' readiness are essential components to deploy e-procurement in the industry successfully. 


\section{References}

[1] Hamma-adama, M., Salman, H., \& Kouider, T. (2020). Blockchain in construction industry: challenges and opportunities. Presented at 2020 International engineering conference and exhibition (IECE 2020), 2-5 March 2020, Riyadh, Saudi Arabia.

[2] Hileman, G., \& Rauchs, M. (2017). Global blockchain benchmarking study. Cambridge Centre for Alternative Finance, University of Cambridge, 122

[3] Risius, M., \& Spohrer, K. (2017). A blockchain research framework. Business \& Information Systems Engineering, 59(6), 385-409.

[4] Gaire, R., Ghosh, R. K., Kim, J., Krumpholz, A., Ranjan, R., Shyamasundar, R. K., \& Nepal, S. (2019). Crowdsensing and privacy in smart city applications. Smart cities cybersecurity and privacy (pp. 57-73) Elsevier.

[5] Zheng, Z., Xie, S., Dai, H., Chen, X., \& Wang, H. (2017). An overview of blockchain technology: Architecture, consensus, and future trends. Paper presented at the 2017 IEEE International Congress on Big Data (BigData Congress), 557-564.

[6] Wang, H., Chen, K., \& Xu, D. (2016). A maturity model for blockchain adoption. Financial Innovation, 2(1), 12.

[7] Davies, R., Crespin-Mazet, F., Linne, A., Pardo, C., Havenvid, M.I., Harty, C. and Salle, R. (2015). BIM in Europe: Innovation networks in the construction sectors of Sweden, France and the UK.

[8] Carney, T.F. (1972). Content analysis: A technique for systematic inference from communications University of Manitoba Press.

[9] Guest, G., MacQueen, K.M., and Namey, E.E. (2011). Applied thematic analysis sage.

[10] Marshall, B., Cardon, P., Poddar, A., \& Fontenot, R. (2013). Does sample size matter in qualitative research?: A review of qualitative interviews in IS research. Journal of computer information systems, 54(1), 11-22.

[11] Trumbull, M. (2005). Qualitative research methods. Integrating Quantitative and Qualitative Methods in Research, 101-126.

[12] Creswell, J.W., and Creswell, J.D. (2017). Research design: Qualitative, quantitative, and mixed methods approaches Sage publications.

[13] Spiggle, S. (1994). Analysis and interpretation of qualitative data in consumer research. Journal of Consumer Research, 21(3), 491-503.

[14] Hamma-Adama, M., Kouider, T., \& Salman, H. (2018). State of building information modelling (BIM) adoption in Nigeria. Working paper presented at the 34th Association of Researchers in Construction Management (ARCOM) annual conference, 3-5 September 2018, Belfast, UK (online), pages 334-343.

[15] F. Sartipi, "Automatic sorting of recycled aggregate using image processing and object detection," Journal of Construction Materials, vol. 1, pp. 3-3, 2020, doi: https://doi.org/10.36756/JCM.v1.2.1. 
[16] T. Boulos, F. Sartipi, and K. Khoshaba, "Bibliometric analysis on the status quo of robotics in construction," Journal of Construction Materials, vol. 1, pp. 2-3, 2020.

[17] F. Sartipi, "A brief critical view on the carbon-conditioning of recycled aggregate using pressure chamber," Journal of Construction Materials, vol. 2, pp. 1-4, 2020, doi: https://doi.org/10.36756/JCM.v2.1.4.

[18] F. Sartipi and A. Sartipi, "Brief review on advancements in construction additive manufacturing," Journal of Construction Materials, vol. 1, pp. 2-4, 2020, doi: https://doi.org/10.36756/JCM.v1.2.4

[19] A. Gharizadeh, F. Sartipi, E. Ayoubi, and A. Severino, "The chemical reactor design configuration of CO2 concrete green solution," Journal of Construction Materials, vol. 1, pp. 2-5, 2020, doi: https://doi.org/10.36756/JCM.v1.2.5.

[20] F. Sartipi, "Diffusion of Innovation Theory in the Realm of Environmental Construction," Journal of Construction Materials, vol. 1, pp. 4-2, 2020, doi: https://doi.org/10.36756/JCM.v1.3.2.

[21] F. Sartipi, "Dynamic data processing for building energy consumption," Journal of Construction Materials, vol. 2, no. 2021, pp. 2-4, 2020, doi: https://doi.org/10.36756/JCM.v2.2.4.

[22] F. Sartipi, "Influence of $5 G$ and IoT in construction and demolition waste recycling-conceptual smart city design," Journal of Construction Materials, vol. 1, pp. 4-1, 2020, doi: https://doi.org/10.36756/JCM.v1.4.1.

[23] F. Sartipi, "Negative interest rate: Way to tackle inflationary housing prices," Journal of Construction Materials, vol. 2, pp. 4-1, 2021, doi: https://doi.org/10.36756/JCM.v2.4.1.

[24] A. Kandiri, F. Sartipi, and M. Kioumarsi, "Predicting Compressive Strength of Concrete Containing Recycled Aggregate Using Modified ANN with Different Optimization Algorithms," Applied Sciences, vol. 11, no. 2, p. 485, 2021, doi: https://doi.org/10.3390/app11020485.

[25] F. Sartipi, "Publicizing construction firms by cryptocurrency," Journal of Construction Materials, vol. 2, pp. 3-1, 2021, doi: https://doi.org/10.36756/JCM.v2.3.1.

[26] M. Sartipi and F. Sartipi, "Stormwater retention using pervious concrete pavement: Great Western Sydney case study," Case Studies in Construction Materials, vol. 11, p. e00274, 2019. 